\title{
Renovação dos estudos em Tillich no Brasil: novos contextos, novas gerações, novas preocupações
}

\author{
Carlos Eduardo Calvani*
}

\section{RESUMO}

O objetivo do presente texto é partilhar com a comunidade acadêmica que se empenha em estudar a obra de Paul Tillich informações sobre as possibilidades de renovação dessas pesquisas em novos contextos e com uma nova geração de pesquisadores e pesquisadoras reunidos em torno do GPCOR (Grupo de Pesquisa Correlativos) na Universidade Federal de Sergipe. Secundariamente, o texto apresenta os objetivos e finalidades do GPCOR destacando dentre eles a linha de pesquisa intitulada "Teologia e Filosofia na obra de Paul Tillich". A partir desse cenário, o texto se desdobra sinalizando iniciativas e eventos, bem como pesquisas desenvolvidas por uma nova geração de estudantes localizada em regiões distantes do sudeste brasileiro. Tais pesquisas apontam interesses particulares nascidos em um contexto marcado pela agressividade da seca e por gritantes diferenças sociais, bem como pela inquietação perante a realidade em uma conjuntura social fortemente marcada pela religiosidade popular e por experiências religiosas entusiásticas. O texto, além de apontar tendências futuras também procura mostrar que a obra de Tillich guarda potenciais mediações teóricas ainda por serem exploradas no Brasil.

Palavras chave - Paul Tillich; Revelação; Êxtase; Correlação; Nordeste brasileiro.

* Professor no Programa de Pós-Graduação em Ciências da Religião da Universidade Federal de Sergipe. 


\title{
RENOVATION OF STUDIES IN TILLICH IN BRAZIL: NEW CONTEXTS, NEW GENERATIONS, NEW CONCERNS
}

\begin{abstract}
The aim of the present text is to share with the academic community dedicated to studying the work of Paul Tillich information on the possibilities of renewing these research in new contexts and with a new generation of researchers gathered around the GPCOR Correlativos) at the Federal University of Sergipe. Secondly, the text presents the objectives and purposes of the GPCOR, highlighting among them the line of research entitled "Theology and Philosophy in the work of Paul Tillich. From this scenario, the text signals initiatives and events, as well as research developed by a new generation of students located in distant regions of southeastern Brazil.Such research points to particular interests born in a context marked by the aggressiveness of the drought and by great social differences, as well as by the unrest towards reality in a social conjuncture strongly marked by popular religiosity and enthusiastic religious experiences. In the end, the text points to future trends and show that Tillich's work holds potential theoretical mediations still to be explored in Brazil.
\end{abstract}

Keywords: Paul Tillich; Revelation; Ecstasy; Correlation. Brazilian Northeast

\section{Introdução}

No mundo acadêmico é comum a aproximação de pesquisadores e pesquisadoras que se atraem a partir da partilha de interesses teóricos semelhantes ou do aprofundamento no estudo da obra de um autor específico. Esse foco faz surgir grupos de pesquisa em várias universidades e associações nacionais que se encontram periodicamente. Assim também surgiu a Associação Paul Tillich, inicialmente como Grupo de Pesquisa na UMESP nos anos 90. Aos poucos, colegas foram se aproximando, simpósios e encontros foram organizados, artigos acadêmicos começaram a surgir bem como coletâneas, dissertações e teses. Parte desse histórico com um primeiro levantamento bibliográfico 
das produções no Brasil foi publicado em 2006 (CALVANI, 2006). Porém, passados doze anos desse primeiro mapeamento, a quantidade de textos baseados em referenciais tillichianos torna essa tarefa bastante difícil. Afinal, embora modestos em visibilidade, os estudos sobre Paul Tillich já começam a aparecer em diferentes universidades, principalmente em Programas de pósgraduação em Filosofia ou em Ciências da Religião. Certamente uma pesquisa de levantamento e interpretação dessa produção exigirá horas de dedicação, leitura e análise, justificando um projeto próprio de financiamento aos que a ela se dedicarem.

Tal constatação indica que o vigor e a densidade do pensamento de um autor pode permanecer adormecido por algum tempo, mas sempre estará lá à disposição de novas gerações que se aproximarão dessa obra com outras preocupações. O presente texto pretende partilhar com a comunidade acadêmica algumas informações sobre a renovação dos estudos em Tillich no nordeste brasileiro, especificamente na Universidade Federal de Sergipe através do GPCOR (Grupo de Pesquisa Correlativos). Os temas pesquisados nos últimos quatro anos apontam interesses muito particulares próprios de um contexto social muito particular e de uma geração que apresenta interesses um tanto diferentes daqueles que marcaram os primeiros estudos acadêmicos sobre Tillich no Brasil. Afinal, como já ensinava Max Weber em sua famosa palestra sobre a ciência como vocação:

na ciência cada qual sabe que aquilo que produziu ficará antiquado dentro de dez, vinte ou cinquenta anos. Tal é o destino, o sentido do trabalho científico (...) toda 'realização' científica significa novas 'questões' e quer ser ultrapassada, envelhecer. Quem pretende dedicar-se à ciência tem de contar com isto. (WEBER, 2005, p. 12)

Desse modo, o texto pretende sinalizar tendências futuras e, ao mesmo tempo, mostrar que a obra de Tillich ainda guarda potenciais mediações teóricas inexploradas no Brasil. 


\section{Novos contextos}

Toda produção humana traz, em maior ou menor grau, as marcas do contexto social, geográfico e histórico na qual surgiu. O mesmo acontece com a pesquisa científica e com a produção teológica. É impossível compreender certas ênfases de Tillich nos anos 20 e 30 sem considerar as circunstâncias nas quais ele viveu, e que nos remetem à guerra de 1914-1918, às crises econômicas e sociais da República de Weimar, aos movimentos artísticos da época e à ascensão do nacionalsocialismo (TILLICH, 1933, 1998). Do mesmo modo, após o exílio, novos interesses ocuparam seu trabalho. O primeiro artigo escrito na América nasce não mais de uma preocupação de engajamento político, mas de marcar a identidade teológica de seu trabalho frente ao crescimento da influência de Barth na América (TILLICH, 1935).

Historicamente, os estudos sobre Tillich no Brasil surgiram em centros acadêmicos das regiões sudeste e sul, reunindo pesquisadores da UMESP (Universidade Metodista de São Paulo) e da EST (Escola Superior de Teologia). Nessas duas universidades também surgiram os primeiros Grupos de Pesquisa, dissertações e teses e as primeiras coletâneas impressas. As reuniões anuais da Associação Paul Tillich também sempre ocorreram no Sudeste brasileiro. Uma breve pesquisa na revista eletrônica Correlatio nos auxilia a perceber que certos temas muito em voga no início dos anos noventa aos poucos foram abandonados, tais como a compreensão do esoterismo e do movimento da nova era. Por outro lado outras preocupações permaneceram recorrentes, notadamente as questões ligadas à arte, à mística, à espiritualidade ou à política. Nos últimos anos pesquisadores têm procurado identificar similaridades e diferenças em questões metateóricas comparando o pensamento de Tillich e o de autores contemporâneos como Vattimo, Girard, Jean-Luc Nancy, ComteSponville e Edgar Morin. Nos números mais recentes surgiram temas como o êxtase, a experiência religiosa em igrejas pentecostais e a experiência religiosa budista no Brasil. Essas preocupações certamente emergem da experiência cultural difusa em grandes centros urbanos nos quais se tenta compreender o embate entre secularização e agora 
dessecularização, e as infindáveis discussões a respeito de modernidade ou pós-modernidade.

A extensão territorial do território brasileiro e as diferenças culturais que fizeram Roger Bastide (1979) qualificar nosso país como "terra de contrastes" impediu por muito tempo que a pesquisa na obra de Tillich atingisse as regiões norte, nordeste e centro-oeste. Ainda assim, preocupações próprias do contexto amazônico já ganharam visibilidade na revista Correlatio através de artigos tematizando a pintura da artista paraense Antonieta Santos Feio (PAES, 2014 e 2016) ou o xamanismo indígena (REIS, 2016). Menções específicas à cultura nordestina só apareceram esporadicamente em um artigo sobre a poética de Belchior (SILVA, 2008) e na análise de uma canção de Caetano Veloso (CALVANI, 2017).

As expressões "contexto nordestino" e "cultura nordestina" merecem certo esclarecimento para evitar generalizações. Há um nordeste litorâneo e urbanizado que recebe a constante visita de turistas, comerciantes e migrantes oriundos de outras regiões do Brasil e que ali se fixam. É também a região mais industrializada e a que concentra o maior número de centros universitários. Mas apenas alguns quilômetros a dentro há o sertão nordestino e a zona do agreste, que Darcy Ribeiro denominou "Brasil sertanejo", confinado geograficamente pela mata atlântica, a floresta amazônica, o litoral e a zona da mata. É uma região de clima quente e árido, acostumada a longos períodos de seca que afetam a regularidade do plantio e da colheita e favorecem a esperança na intervenção de agentes sobrenaturais. Não por acaso, é uma região que já viveu fortes surtos messiânicos e milenaristas (Antônio Conselheiro, por exemplo, ou os "Borboletas azuis" na Paraíba) e onde, até hoje, a influência de discursos de autoridade religiosa é muito forte, seja através da figura mítica de líderes religiosos já falecidos (Padre Cícero de Juazeiro do Norte ou Frei Damião, de Pernambuco), da autoridade coronelista de pastores evangélicos ou mesmo do respeito que grande parte da população tem por lideranças afro (Mãe Menininha do Gantois, por exemplo). Conforme Ribeiro,

o sertanejo arcaico caracteriza-se por sua religiosidade singela tendente ao messianismo fanático, por seu carrancismo de hábitos, por seu laconismo e rusticidade, por sua predisposição ao sacrifício e à violência. 
E ainda, pelas qualidades morais características das formações pastoris do mundo inteiro, como o culto à honra pessoal, o brio e a fidelidade a suas chefaturas (RIBEIRO 1996 p. 340).

Em um contexto como esse, a religiosidade popular é muito forte e viva, mas ao mesmo tempo, crítica. O respeito ao catolicismo e a seus representantes oficiais, embora forte, é temperado por certa desconfiança para com a Igreja. Em todo caso, ali o catolicismo popular sempre se reinventa através de atividades paralitúrgicas (rezas, novenas, procissões e festas) lideradas por irmandades de leigos e beatas, muitas vezes sem permissão ou autorização da Igreja. Essa religiosidade tem um ciclo próprio que não se vincula necessariamente ao calendário litúrgico oficial, mas aos ciclos da vida familiar (nascimento, casamento, doença, morte) ou socioeconômica (seca, preparo da terra, plantio e colheita). A festa de São João, por exemplo, é uma típica festa agrícola pré-cristã que celebra a colheita do milho e a fartura da natureza.

Impossível esquecer também os inúmeros e incontáveis santuários de ex-votos onde fieis deixam réplicas em cera de órgãos do corpo que foram curados ou regenerados pela ação milagrosa de algum santo ou santa, mesmo que não reconhecido oficialmente pela Igreja, como é o caso do Padre Cícero Romão Batista. Em São Cristóvão, por exemplo, cidade vizinha a Aracaju, recentemente o bispo católico decidiu criar um museu com imagens antigas de santos e santas que estavam esquecidas e empoeiradas nas sacristias. Os vigários recolheram essas imagens e após um processo mínimo de restauração, o museu foi inaugurado. O espaço idealizado para ser um local de turismo e comercialização de artigos religiosos, aos poucos se tornou centro de peregrinação religiosa, com muitas pessoas ajoelhadas e rezando aos pés das imagens e depositando ali moedas, fotografias de parentes desaparecidos, falecidos ou com problemas de saúde e até mesmo peças típicas de ex-votos, além de velas acesas. O prof. Dr. Luís Américo Silva Bonfim, colega do Programa de Pós-Graduação em Ciências da Religião da Universidade Federal de Sergipe (UFS) vem desenvolvendo extensa e qualificada pesquisa acadêmica de catalogação e interpretação das expressões votivas da religiosidade popular nordestina e seus textos publicados no Brasil e no exterior têm evidenciado a importância de dar atenção ao "locus" da religiosidade popular (BONFIM, 2013, 2015a, 2015b, 2015c.). 
Em tal contexto, palavras e conceitos como "secularização", "pósmodernidade" e "desencantamento do mundo" dificilmente encontram eco. A maior parte da população não vive em um mundo desencantado, mas encantado, em pequenos povoados onde não há água encanada e esgoto e há constantes quedas de energia elétrica (em alguns povoados ainda se utiliza gerador de eletricidade). São lugares onde ainda se pede a bênção ao pai e à mãe e onde os sinos ainda badalam aos domingos chamando o povo para a missa. Como poemizou Mário Quintana, "só nessas cidadezinhas humildes é que ainda o chamam de Deus Nosso Senhor..." (QUINTANA, 1980).

Nesse contexto sem antenas de telefonia celular próximas, sem internet ou televisões a cabo, onde ainda se dá muito valor a agentes sobrenatruais, santos e santas, anjos e orixás, almas e pavões misteriosos, a pesquisa em Teologia e Ciências da Religião certamente demanda outras perguntas. O "objeto-religião" é vivo, dinâmico, fluído, afirma e desafirma, fala e logo depois se contradiz. É este "objeto" (as experiências religiosas) que determina a pesquisa e não propriamente nós, pesquisadores que afirmamos o que ele, o "objeto-religião", deva ser.

\section{Novas gerações - O Grupo de Pesquisa Correlativos (GPCOR - UFS)}

Em 2014, por iniciativa do prof. Dr. Joe Marçal Gonçalves dos Santos e do autor dessas linhas, foi criado o Grupo de Pesquisa Correlativos - Estudos em Cultura e Religião (GPCOR) na Universidade Federal de Sergipe. A escolha do nome traz nítidas influências tillichianas ao fazer menção ao método da correlação. Aos poucos foram aparecendo estudantes interessados em apropriarse de um referencial que lhes oferecesse possibilidades teóricas de compreender a presença e o impacto de discursos e símbolos religiosos na cultura local. Cadastrado no Diretório do CNPQ, o Grupo conta hoje com três professores-pesquisadores e dez estudantes agrupados em quatro linhas de pesquisa: a) Criatividade cultural e sentido religioso na cultura contemporânea; b) Filosofia, Literatura e Religião; c) Religião, Literatura e Modernidade; d) Teologia e Filosofia na obra de Paul Tillich. 
As primeiras atividades foram tímidas e se iniciaram com um círculo de leitura em que foram apresentadas informações sobre a vida e obra de Tillich e o método da correlação. Os professores sugeriram temas e textos para uma sequência de leituras dirigidas e a escolha dos estudantes foi pelo livro Dinâmica da Fé. No ano seguinte, em 2015, com um grupo maior de estudantes envolvidos, o GPCOR organizou o I Ciclo de Estudos com o tema "Paul Tillich: 50 anos depois - a atualidade de seu legado", realizado na UFS no mês de novembro. O evento lembrava os 50 anos da morte de Tillich e contou com palestras dos pesquisadores e uma mostra audiovisual sobre o contexto sóciopolítico dos anos de 1920 e 1930. O evento despertou muito interessante entre estudantes do curso de Licenciatura em Ciências da Religião da UFS e contou com 120 inscrições.

No ano seguinte (2016), aproveitando o mesmo tema do encontro anual da Associação Paul Tillich, organizou-se um novo ciclo de leituras sobre o conceito de ambiguidade, baseado na leitura sequencial e comentada do volume III da Teologia Sistemática. Os pesquisadores compreendem que esse ainda é um período de formação teórica para apropriação mais precisa dos conceitos operacionais da obra de Tillich. No mesmo ano, os pesquisadores conseguiram aprovar dois projetos de iniciação científica (PIBIC) ligados ao GPCOR. Um deles tratava especificamente do conceito de revelação na Teologia Sistemática e seus resultados foram apresentados na Semana de Iniciação Científica da UFS pelo estudante Renaldo Bonfim, orientado pelo prof. Carlos Eduardo Calvani. O segundo projeto, ligado à linha de pesquisa "Religião, Literatura e Modernidade" e organizado pelo prof. Dr. Joe Marçal Gonçalves dos Santos focalizou-se na obra do poeta paraibano Augusto dos Anjos e intitulou-se "O vazio sagrado da poesia de Augusto dos Anjos: aproximações teórico-metodológicas entre literatura e religião". Na justificativa do projeto, o professor proponente lembrava que "a noção de "vazio sagrado" remete a Tillich (1990a, 1990b) como possibilidade de interpretar a condição humana marcada pela ausência da experiência e do conhecimento de Deus" (SANTOS, 2015). Esse projeto contou com duas bolsistas - Laudileia Valença da Silva e Luciana dos Santos Bomfim - na época graduandas do curso de Ciências da Religião, e que seguiram diferentes planos de trabalho e 
também foi apresentado publicamente na Semana de Iniciação Científica da UFS. Atualmente o projeto segue com outro bolsista de Iniciação Científica, Ivanilton Aragão, graduando do curso de Letras, tratando especificamente do tema orientalista em Augusto dos Anjos. Vale lembrar que este projeto, em grande medida foi elaborado, a partir da oferta da disciplina "Literatura e Religião" no Programa de Mestrado em Ciências da Religião, ofertada pelo prof. Joe Marçal e que resultou também na publicação de um artigo (SANTOS, 2014).

Ainda no âmbito do Programa de Mestrado, O Prof. Joe Marçal dos Santos ofertou em 2015.2, a disciplina "Tópicos em Filosofia da Religião", abordando os textos compilados por James Luther Adams em What is religion (TILLICH, 1973). Por sua vez, no $1^{\circ}$. Semestre de 2017, o professor Carlos Eduardo Calvani ofereceu a disciplina "Linguagem e Religião" na qual foi possível aprofundar a leitura e debate de toda parte I da Teologia Sistemática (Introdução, Razão e Revelação, O Ser e Deus) e, no semestre seguinte (2017.2), o Prof. Joe Marçal, novamente na disciplina "Tópicos em Filosofia da Religião" abordou as noções de mistério, revelação e êxtase como categorias de "fronteira" entre estética e religião em Tillich.

O II Ciclo de Estudos do GPCOR foi organizado no ano de 2017 com o tema "Reforma Protestante, 500 anos depois: fontes e repercussões". Com uma programação mais extensa, o evento contou com duas tardes dedicadas à partilha de comunicações científicas de estudantes ligados aos projetos de iniciação científica e também aos demais estudantes do curso de Mestrado. As noites foram reservadas para palestras nas quais foi aprofundada a interpretação tillichiana das relações entre Reforma e Modernidade e seus desdobramentos. Com tais eventos o GPCOR iniciou o ano de 2018 com maior visibilidade na UFS e a incorporação de novos pesquisadores que se reúnem mensalmente para compartilhar os resultados parciais de suas pesquisas.

\section{Novas preocupações}

Atualmente, um novo projeto de iniciação científica está em andamento, coordenado pelo prof. Carlos Eduardo Calvani com o título "Influências neoplatônicas de Schelling no pensamento de Tillich". O 
projeto previa dois planos de pesquisa, mas com a aprovação de apenas um desses planos, a cargo do estudante Bruno Franco Neves, uma considerável mudança teve que ser empreendida, limitando o projeto à leitura, interpretação e tradução de trechos da primeira tese de doutorado de Tillich sobre o conceito de história das religiões no pensamento de Schelling (TILLICH, 2010/1974a). Em fase de conclusão e a ser apresentado em setembro, o projeto foi renovado para o período 20182019 focalizando-se na leitura, interpretação e tradução de trechos da segunda tese de Tillich sobre misticismo e consciência de culpa na filosofia de Schelling (TILLICH, 1974b).

No âmbito do Mestrado em Ciências da Religião, ao menos duas pesquisas da nova geração se apropriam, de alguma maneira de referenciais tillichianos ou buscam em seus textos algum apoio teórico. Ambas estão em fase de qualificação e esperamos que, uma vez aprovados em defesa de dissertação pública, seus resultados possam ser compartilhados com a comunidade acadêmica que se une em torno da Associação Paul Tillich. Uma dessas pesquisas intitula-se provisoriamente, "Êxtases do eu em um mundo dilacerado", resultado do PIBIC desenvolvido por Luciana dos Santos Bomfim e sob a orientação do prof. Dr. Joe Marçal Gonçalves dos Santos. Os primeiros resultados da pesquisa já foram apresentados no ciclo mensal do GPCOR e nela, os conceitos de êxtase, revelação, mistério e evento-sinal são utilizados como referenciais de análise de poesias de Augusto dos Anjos.

A segunda pesquisa de Mestrado em andamento e também em fase de qualificação é a de Almir Lima Andrade, que problematiza criticamente o conceito de "princípio profético protestante" na teologia de Tillich, em especial o modo como o teólogo interpreta o movimento profético do antigo Israel, privilegiando o elemento ético e negligenciando o elemento extático ou dando-lhe outras feições nitidamente comprometidas com a tradicional desconfiança que os teólogos luteranos sempre tiveram para com movimentos entusiásticos desde os tempos da Reforma. A hipótese que norteia o projeto é a de que, nos anos vinte e trinta Tillich elaborou um "tipo ideal" de profeta que não corresponde em sua inteireza à totalidade do movimento profético, equiparando-o a um típico analista da conjuntura social ao estilo de seus colegas do socialismo religioso e do círculo que veio 
a formar a Escola de Frankfurt. A pergunta maior é se não pairava em Tillich certo preconceito para com experiências entusiásticas assemelhadas a transes xamânicos ou a visões sobrenaturalistas muito presentes na religiosidade popular. Afinal, na argumentação de Tillich, êxtase é o aspecto subjetivo da revelação e milagre-sinalevento é o aspecto objetivo da revelação. Porém, tanto ao êxtase quanto ao milagre (sinal-evento) estão expurgadas outras facetas bem próximas à religiosidade popular: o transe e a magia. Para Tillich essas manifestações não são propriamente revelação. Transe é o elemento negativo do êxtase (ou seja, aquilo que não é revelação) e magia é o elemento negativo do milagre (ou seja, aquilo que também não é revelação). Nesse caso, mais uma vez, o protestantismo se apresenta como baseado em um princípio profético ético e racional e distante da religiosidade popular que tanto valoriza experiências de transe e magia.

\section{Considerações finais}

Novos contextos, novas gerações e novas preocupações. A renovação dos estudos tillichianos, ao menos no Nordeste brasileiro tem se anunciado desafiadora. Observamos que nos dois projetos de Mestrado atualmente em curso, o conceito de êxtase é central. Em ambos, o conceito é trabalhado a partir dos textos que melhor sustentam a argumentação tillichiana, ou seja, a parte I da Teologia Sistemática na qual se discute a relação entre razão e revelação.

É preciso, porém, lembrar que o título que Tillich dá à seção dedicada à revelação é “A realidade da revelação". Realidade é uma palavra forte e certamente evoca o antigo realismo que Tillich buscava recuperar em novos moldes. Enquanto teólogo, Tillich nesse caso é enfático: a revelação não é uma ilusão, uma imaginação ou mero jogo de linguagem. A revelação é uma realidade! O absoluto, o incondicional ("Deus", na linguagem teológica, abismo e fundamento) se revela! A revelação foi e é possível, e aponta para a superação dos conflitos entre autonomia e heteronomia, absolutismo e relativismo, formalismo e emocionalismo. No âmbito do GPCOR tal assunto tem sido tematizado em virtude da coerência com o próprio nome do Grupo - "Correlativos". Afinal, o método da correlação implica o pressuposto da revelação, 
buscando o equilíbrio entre duas instâncias aparentemente estranhas e adversas (razão e revelação), mas que, no método, se equilibram e dialogam sem que nenhuma esteja subordinada à outra, embora a revelação sempre venha suprir as carências da razão e responder às suas perguntas.

Se essa é uma assertiva para qualquer teólogo, o passo seguinte, e o mais difícil, é tentar compreender a natureza dessa revelação. A realidade de um mundo que se apresenta ao poeta como dilacerado, bem como os atos, palavras, oráculos e a literatura atribuída a profetas ou a seus seguidores podem ser revelatórios. A pergunta que pode nos fazer repensar teoricamente muito do que já escrevemos sobre "princípio profético", é: por que o transe e a magia não têm lugar positivo na teologia de Tillich? São novas perguntas e preocupações teóricas trazidas pelas novas gerações. Afinal, Weber já nos alertava: "ser cientificamente ultrapassado não é só o destino de todos nós, mas também toda a nossa finalidade. Não podemos trabalhar sem esperar que outros hão de ir mais longe do que nós. Este progresso, em princípio, não tem fim" (WEBER, 2005, p. 12).

\section{Bibliografia}

BASTIDE, Roger. Brasil, terra de contrastes, São Paulo: Difel, 1979.

BONFIM, Luís Américo Silva. A expressão votiva católica na época de sua reprodutibilidade técnica. Campos (UFPR), v. 13, p. 9-22, 2013.

. Folk Saints in South America. In: POLK, Patrick A. (org).

Sinful Saints and Saintly Sinners at the Margins of the Americas. 1a ed. Los Angeles, CA: University of California/UCLA, 2015a, v. 1, p. 46-57.

. Reinvenção do sagrado: as práticas votivas populares e seus desdobramentos institucionais no nordeste do Brasil. In: ANDRADE, Péricles. Polifonia do sagrado: pesquisas em Ciências da Religião no Brasil. $1^{\mathrm{a}}$ ed. São Cristóvão-SE, Editora UFS, 2015b, v. 1, p. 153-165.

Cultos e canonizações populares no nordeste do Brasil: notas etnográficas sobre processos de reparação post-mortem. In: $2^{\circ}$. Simpósio Nordeste da ABHR, 2015, Recife-OE, Anais dos Simpósios da ABHR, 2015c, p. $1-16$

CALVANI, Carlos Eduardo. A recepção do pensamento de Tillich no Brasil. Correlatio n. 10, novembro de 2006, p.152-182. 
. Existirmos... a que será que se destina? Choque ontológico, angústia e coragem de ser na canção Cajuína. Correlatio v. 16, n.1, 2017, p.99-113.

PAES, Francisco Augusto Lima. Paul Tillich e a pintura amazônica de Antonieta Santos Feio: Interfaces entre arte e religião na tela Mendiga (1951) Correlatio, v. 13, n. 26, 2014, p.71-95.

- Vestígios do sagrado: a obra de arte como possibilidade de mediação entre religião e cultura na pintura de Antonieta Santos Feio. Correlatio v. 15, n. 2, 2016, p. 123-150.

QUINTANA, Mário. As cidades pequenas. In: QUINTANA, Mário. Esconderijo do Tempo. Porto Alegre: Objetiva, 1980.

REIS, Gustavo Soldati. O xamanismo indígena guarani como expressão demônica da cultura. Correlatio, v. 15, n. 2. 2016, p. 199-208.

RIBEIRO, Darcy. O povo brasileiro - a formação e o sentido do Brasil. São Paulo: Companhia das Letras, 1996.

SANTOS, Joe Marçal Gonçalves. Viagem de um vencido, de Augusto dos Anjos: literatura, religião e modernidade em perspectiva teológica. Paralellus, v. 5 , n. 10,2014 , p. $233-249$.

. O 'vazio sagrado' da poesia de Augusto dos Anjos: aproximações teórico-metodológicas entre literatura e religião - Projeto PIBIC PVD31032015.

SILVA, Natanael Gabriel da. Profecia, existência e Teologia da Cultura na poética de Belchior. Correlatio, v 7, n. 14, 2008, p.88-100.

TILLICH, Paul. The Socialist Decision (1933). Translated by Franklin Sherman. New York: Harper \& Row, Publishers, 1977.

."What Is Wrong with the 'Dialectic Theology?" The Journal of Religion 15, no. 2 (Apr., 1935): 127-145

. The construction of the History of Religion in Schelling's Positive Philosophy - its presuppositions and principles. (Translated with an introduction and notes by Victor Nuovo). London: Bucknell University Press, 1974a.

Mysticism and Guilt-Consciousness in Schelling's

Philosophical Development. (Trans. by Victor Nouvo). Lewisburg: Bucknell University Press, 1974b.

. Existencialist aspects of Modern Art (1956). In.: PALMER, Michael (Ed.). Paul Tillich's Main Works - volume 2: writings in the Philosophy of Culture. Berlin: New York: De Gruyter, 1990a, p. 269-280. 
Protestantism and the Contemporary Styles in Visual Arts (1957). In.: PALMER, Michael (Ed.). Paul Tillich's Main Works - volume 2: writings in the Philosophy of Culture. Berlin: New York: De Gruyter, 1990b, p. 297-302.

What is religion? New York: Harper and Row, 1973.

. Against the Third Reich - Paul Tillich's wartime addresses

to nazi Germany (org. Mutie Tillich Farris). Louisville, John Knox Press, 1998.

WEBER, Max. A ciência como vocação. In: Três tipos de poder e outros escritos (Trad. Artur Mourão), Tribuna da História, Lisboa, 2005. 